\title{
Suicide Attempts in Adolescents
}

\author{
Ivanova Veronika \\ Medical University of Varna, Varna, Bulgaria \\ Email: veronika_ivanovi@abv.bg
}

How to cite this paper: Veronika, I. (2021). Suicide Attempts in Adolescents. Psychology, 12, 749-755.

https://doi.org/10.4236/psych.2021.125046

Received: April 28, 2021

Accepted: May 24, 2021

Published: May 27, 2021

Copyright (c) 2021 by author(s) and Scientific Research Publishing Inc. This work is licensed under the Creative Commons Attribution International License (CC BY 4.0).

http://creativecommons.org/licenses/by/4.0/

\begin{abstract}
The purpose of this article is to present the psychodynamics of the experiences of adolescents who have attempted suicide by attempting to explore the relationships between the desire to die and the early experience of disintegration. During the hospital stay, psychotherapy sessions were conducted with 40 adolescents ( 28 girls), age 12 - 19, after suicide attempt. An analysis of the data from the protocol records of the sessions with adolescents, we use qualitative interpretative analysis and the main themes, are analyzed in their experiences. The results of content analysis provide a link between the early experiences of mental death from abandonment, which remained unprocessed, and the real desire for suicide, taking into account the role of psychotherapeutic contact, which promotes awareness and pronunciation in words of these experiences, eliminating the unconscious need for their realization in the present. Therapeutic contact, with therapy, focused on the "here and now" modality, helps to create a new object connection between the adolescent and the therapist, which will help the awareness and integration of the early experiences of abandonment by parents.
\end{abstract}

\section{Keywords}

Early Trauma, Adolescents, Suicides, Inpatient Psychotherapy

\section{Introduction}

The attempts at suicide in adolescents are not always so easy to recognize in practice, they can conceal under increased interest in high extreme sports, frequent fractures, random poisoning. For parents and specialists, it is difficult and challenging to talk about death, especially in the adolescent, which makes the situation dangerous.

There are different views of the authors, generally dividing them into psychoanalytic and oriented more to behavioural psychology (Elia, 2019; Readdick, 
2008; Corey, 1996; Caballo \& Simón, 2001; Bragado Álvarez et al., 1995). Safer (1997) is trying to find adolescent-adult differences in suicidal behavior. He says they are "similar with respect to their gender ratio, adolescent are different from adults in suicidal behavior in their greater attempt rate, higher attempt/completion ratio, and lower rates of short and intermediate completion following psychiatric treatment”. Other scientists (King et al., 2020) derived 5 profiles of elevated suicide risk with differing patterns of risk factors: history of multiple suicide attempts, past-month suicidal ideation, depression, alcohol and drug misuse, impulsive-aggression, and sexual and physical abuse.

The other point of view is psychodynamic, there with the problem of adolescence suicide actively engaged in authors as (Dolto, 1995, 2020; Delarosh, 2004, 2009, 2011; Casement, 1985). In the psychodynamic approach experience surveys will allow to distinguish the melancholic sense of loss from the true adolescent depression. In most adolescents, there is no full awareness of motivation to put an end to life. Most indicate as a reason separation with a loved one, but in the process of working and deepening the process, through various therapeutic dynamic techniques leads to the basic sense of loss. One of the boys repeated their attempts to suicide, on the day his mother had abandoned him when he was three. Another thought he had made the experience because of the separation with his girlfriend, but it turned out he recently became familiar with his father who thought he had been dead, they had a month to communicate and the father suddenly dies. Much of the random is also of teenagers who do not know they are adopted. A girl made suicide attempts after being cruelly beaten by her father, in front of the mother's eyes, and early psychos were neglected. Another teenager came that the reason for her experience was parting with her boyfriend, but in all her projections came the traumatic relationship with the mother.

The number of depressed children who want to die is much higher than we dare to think and talk about. Dolto encourages adults to talk openly with teenagers about death (Dolto 1995), to talk about adolescence is to talk about death. This is the reason for the growing interest in murder films, horror films during this period. The subject of death attracts and terrifies the teenager. The hope is that the risk of suicide decreases in direct proportion to the ability to express these thoughts, to share with an adult. Dolto writes "the subject despises himself and because he accepts that he deserves nothing but contempt, he despises the person who cares for him" (Dolto, 1995). Melancholy, inferiority, self-blame, and self-destructive behaviour are also found in the stories of these children's parents. Once heard and understood, teenagers no longer feel the need to show their despair. Adults are afraid to talk about death, Dolto continues (Dolto, 1995), they cover it up, remain silent, believing that this is how they protect their children. It is not uncommon for a teenager to attempt suicide, and parents say they avoid talking to him about it so as not to injure him. But this is exactly what he wants to be said, the unspoken. Dolto says, "If you ask a teenager if he thinks about death, the answer is I only think about you." Here is the role of the psy- 
chotherapist, who is an outsider who will not tell the parents what is shared, this may not be a psychotherapist, but someone from the family, usually an aunt or grandmother, who will keep secret and will love and understand without judging them or share with their parents.

Delarosh (2011) notes that suicide attempts are a consequence of the belief that no one deserves the trust of the adolescent, that there is no one to talk to about what excites him. This loneliness can be deadly, the loss of trust in others, the loss of confidence that someone is genuinely interested in them (Basile, 1997, 2002). This loneliness can be deadly, the loss of trust in others, the loss of confidence that someone is genuinely interested in them (Short \& Nemeroff, 2014). It is rarely possible for the dialogue about death to take place before the suicide attempt, the meeting with the specialist is usually after that. This allows you to talk to the adolescent, and it is important for the therapist to recognize the significance of what happened, not to hint at manipulation or dramatization, this would discourage and repel the teenager. Sometimes the suicide attempt, Delaroche writes, is enough to help the teenager see the situation in a different light precisely because the attempt failed, it helps recovery. The main hypothesis of the study early separation trauma is related to the child's identification with the adult's desire not to exist, and during adolescence, usually provoked by love disappointment or separation, leads to suicidal ideation.

\section{Materials and Methods}

During the hospital stay, psychotherapy sessions were conducted with 40 adolescents (28 girls), age 12 - 19, after suicide attempt. The data from the protocol records of the sessions with them, with qualitative interpretative analysis and the main themes, are analyzed in their experiences. The data from the protocol records of the sessions with them, with qualitative interpretative analysis and the main themes, are analyzed in their experiences. For the purposes of the study, we have used quality methods: interpretive phenomenal analysis, contingent analysis. "Qualitative data analysis is a descriptive method. He works with texts in the form of verbal and written speech. The content of the text is of paramount importance in this analysis. But apart from the directly expressed content, the speech also translates the emotional state of the speakers, the attitude to what the partner says, the unconscious contexts...” (Djonev, 2015).

\section{Results}

Stages of the study and thematic analysis, Stages of the study and thematic analysis, 1) Interpretive phenomenal analysis is a method that is used when we are interested in the way a person experiences some phenomenon and, accordingly, the psychological interpretation of that experience. 2) Content analysis is a method of empirical analysis of the content of text. Its characteristic is the reporting of the frequency of certain speech units or thought categories and on this basis an assessment of the back to-back psychic concepts (Djonev, 2015). 
- Categorization of topics and their grouping with a predominance of shared experiences:

$\checkmark$ Death

$\checkmark$ Abandonment

$\checkmark$ Lack of meaning, self-aggression and destruction

$\checkmark$ Loss of meaning

$\checkmark$ Connection, connection, attitude

$\checkmark$ Hope, consolation

- The next stage of the study categorizes the words and sentences most commonly used by teenage patients during the sessions to describe themselves, their past relationships, and those in their relationship with the therapist.

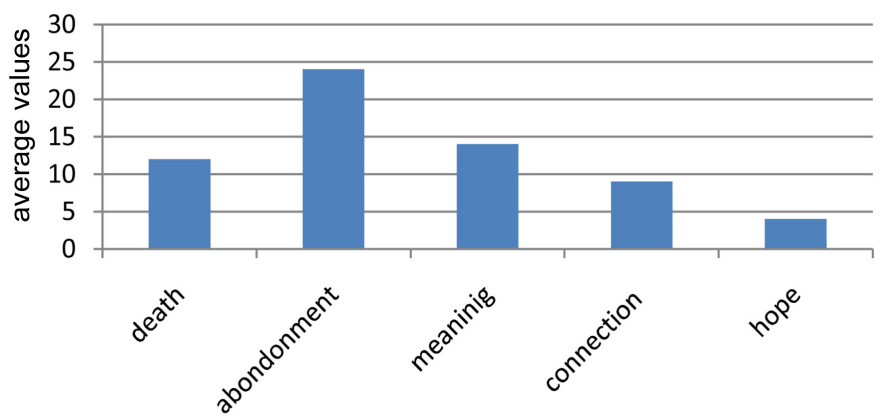

Figure 1. Frequency of manifestation of different contents analysis.

(The results of content analysis) (Figure 1) the table with content analysis is too large to be in the text, shows that words and sentences can be divided into several main categories: 1) death-real and existential anxiety. 2) abandonment, separation-the primary separation and the subsequent sections. 3) Lack of meaning, self-aggression and self-destruction 4) connection, togetherness 5) hope consolation. Words and expressions predominate mainly in the category of separation and the feeling of loneliness and abandonment, which in psychotherapy sessions unfolds as more than a specific event, as an internal lack of connection with part of oneself, the next most pronounced category is that of lack of meaning and only then comes that of death and self-aggression, which confirms the hypothesis that the basis of the desire to commit suicide is precisely the feeling of loss in the sense of reality, but especially in the sense of loss of part of oneself, an unintegrated self, fragile and helpless, despite its outwardly aggressive behavior.

\section{Discussion}

The results show that a relationship between early traumatic experiences of abandonment from the parent can be sought (not in all existence, but there is such basic predefinition in the adolescent). Some of them appear a fear of death, but in a deepening, it is clear that this is the fear of its death, but by that of the parent. We could assume that these children feel deeply angry, usually, in the 
therapeutic process it turns out that this wrath is to parents, though they reveal it indirectly and extremely difficult to talk about it. In the shares of some of them, they imagined how they perform a parent murder, and yet they had difficulty connecting this deep anger with their desire to destroy themselves. The condensation of the states of pain is a way to stay connected to their mothers, keep it attending when they were abandoned. Speech can release the human being if it succeeds through it to express his suffering, before the one who listens to him with attention. Aggression manifests itself in a desire for self-destruction without having a real motivation rationale for this. The removal of one connection, a merger that is characteristic of a much earlier age is believed in their words. And most importantly, hope is also present. The adolescent has reached a situation of the crisis has returned to earlier stages of development, cannot cope with it alone, seek help alone unless someone feels this need in him and does not reach out first hand. The appeal in this case is to the restraining "mother" power of the therapist. The main function of the psychotherapist here is to recognize the importance of the adolescent's experiences. To blunt the suffering, the adolescent needs symbolization, which can only happen through speech, play, history (Elia, 2019). Crisis counselling in such a situation cannot be postponed (Saxe, Ellis, \& Kaplow, 2007). The requirement is immediate. The consultation cannot be postponed, because a person cannot function for a long time at such an intensity of emotion and needs a consultation at that moment (Short \& Nemeroff, 2014). The goal is through psychotherapeutic contact and building a new object relationship with the therapist, emotional and mental death, to be pronounced as a conscious experience, so that there is no need to be an experience in the present. The adult needs to accept that the questions of death are questions of life questions of meaning and should not be overlooked. The duration unlike the standard session, which is about 45 minutes, the crisis session may last longer, it ends when the person can handle its available resources. The adolescent has come to the sitting of the crisis has returned to earlier stages of development, cannot cope with this, seek help alone unless someone feels this need and does not reach out. The main function of psychotherapists here is to recognize the significance of the adolescent experiences. To blur the suffering, the adolescent needs a symbolization that can only happen through speech, the game, the story so managed to reduce the power of emotions while integrating them into its history, not deleting them. The suicide attempt is problematic to the meaning of life, in such situation it is important to understand what is what makes the teenagers continue to live, why does life choose to death, the very talk about the feeling of death inside them helps to break free From it, not the attempts to lift the spirit that lead to the opposite (Dolto, 2020). In consultation after an attempted suicide, it is important to understand what makes the adolescent chose life "I cannot do anything but talking about what makes you live." Support at this time and the hearing helps the adolescent to integrate into its history what happened, understanding the meaning that brings and not to delete it and suppress it. Storytelling allows finding meaning in suffering. 


\section{Conclusion}

In conclusion, we can say that it is possible to look for links between the experiences of loss and early traumatic suicide sections in adolescence. The little child recognizes the abandonment, neglect, indifference and rejection of the mother as a mortal danger. In the therapeutic process, it will deprive this "coercion for repeat" and desire to destroy oneself by building a non-authoritarian therapeutic relationship in which the relation between current and past experiences are delicately looking for.

It is hard to give the recommendations, but there are two very important therapeutic abilities: the psychotherapist needs to be open and courageous, and the possibility to listen in that way, non-judging and accepting to create a story by the trauma, in the symbolic space of speech which can heal.

\section{Conflicts of Interest}

The author declares no conflicts of interest regarding the publication of this paper.

\section{References}

Basile, H. (1997). Terapia de Intervención en Red, en Grupos en Riesgo Psicosocial. Conceptos. Universidad del Museo Social Argentino, 72.

Basile, H. (2002). Depresion I suicido infant juvenile diagnostico precoz I prevencion psicosocial. 3-ro Congreso Virtual de Psiquiatría.

Bragado Álvarez, C. et al. (1995). Prevalencia de los trastornos psicopatológicos en niños y adolescentes. Resultados preliminares. Clínica y Salud, 6, 67-83.

Caballo, V. E., \& Simón, M. A. (2001). Manual de Psicología clínica infantil y del adolescente. Trastornos generales (pp. 2-4). Madrid: Pirámide. Capítulos.

Casement, P. J. (1985). On Learning from the Patient. London: Tavistock Publications.

Corey, G. (1996). Theory and Practice of Counseling and Psychotherapy (5th ed.). Pacific Grove, CA: Brooks/Cole.

Delarosh, P. (2004). Adolescence. Sofiq: Center for Psychosocial Support.

Delarosh, P. (2009). Should He Give in to Teenagers. Sofiq: Center for Psychosocial Support.

Delarosh, P. (2011). The Problems of Adolescence. Sofiq: Center for Psychosocial Support.

Djonev, S. (2015). Qualitative Research Methods in the Social Sciences. Sofiq: ENGB Consulting.

Dolto, F. (2020). How to Talk about the Death. Sofiq: Colobri.

Dolto. F. (1995) Teenegers [Тинейджърите]. Sofia: Nauka I Izkustvo.

Elia, J. (2019). Comportamiento suicida en niños y adolescents. Sidney Kimmel Medical College of Thomas Jefferson University. Última revisión completa mar.

King, C. A., Brent, D., Grupp-Phelan, J., Shenoi, R., Page, K., Mahabee-Gittens, E. M., Chernick, L. S., Melzer-Lange, M., Rea, M., McGuire, T. C., Littlefield, A., \& Casper, T. C. (2020). Pediatric Emergency Care Applied Research Network (PECARN). Five Profiles of Adolescents at Elevated Risk for Suicide Attempts: Differences in Mental Health Service Use. Journal of the American Academy of Child \& Adolescent Psychiatry, 59, 
1058-1068.e5. https://doi.org/10.1016/j.jaac.2019.10.015

Readdick, C. A. (2008). Review of Collaborative Treatment of Traumatized Children and teens: The Trauma Systems Therapy Approach [Review of the book Collaborative Treatment of Traumatized Children and Teens: The Trauma Systems Therapy Approach, by G. N. Saxe, B. H. Ellis \& J. B. Kaplow]. Traumatology, 14, 107-108. https://doi.org/10.1177/1534765608319322

Safer, J. (1997). Adolescent/Adult Differences in Suicidal Behavior and Outcome. Annals of Clinical Psychiatry, 9, 61-66. https://doi.org/10.3109/10401239709147774

Saxe, G. N., Ellis, B. H., \& Kaplow, J. B. (2007). Collaborative Treatment of Traumatized Children and Teens: The Trauma Systems Therapy Approach. New York: Guilford Press.

Short, A. T. O., \& Nemeroff, C. (2014). Early Life Trauma and Suicide. In K. Cannon, \& T. Hudzik (Eds.), Suicide: Phenomenology and Neurobiology (pp. 187-205). Cham: Springer. https://doi.org/10.1007/978-3-319-09964-4 11 